\title{
Men's preferences for the treatment of lower urinary tract symptoms associated with benign prostatic hyperplasia: a discrete choice experiment
}

This article was published in the following Dove Press journal:

Patient Preference and Adherence

24 November 2016

Number of times this article has been viewed

\author{
Colette Mankowski ${ }^{1}$ \\ Divine Ikenwilo ${ }^{2, \dagger}$ \\ Sebastian Heidenreich ${ }^{2}$ \\ Mandy Ryan ${ }^{2}$ \\ Jameel Nazir' \\ Cathy Newman' \\ Verity Watson ${ }^{2}$ \\ 'Health Economics and Outcomes \\ Research, Astellas Pharma Europe \\ Ltd., Chertsey, ${ }^{2}$ Health Economics \\ Research Unit, University of \\ Aberdeen, Aberdeen, UK \\ †Dr Ikenwilo passed away on \\ November 27, 2015
}

Objective: To explore and quantify men's preferences and willingness to pay (WTP) for attributes of medications for lower urinary tract symptoms associated with benign prostatic hyperplasia using a discrete choice experiment.

Subjects and methods: Men in the UK aged $\geq 45$ years with moderate-to-severe lower urinary tract symptoms/benign prostatic hyperplasia (based on self-reported International Prostate Symptom Score $\geq 8$ ) were recruited. An online discrete choice experiment survey was administered. Eligible men were asked to consider different medication scenarios and select their preferred medication according to seven attributes: daytime and nighttime (nocturia) urinary frequency, urinary urgency, sexual and nonsexual side effects, number of tablets/day, and cost/month. A mixed-logit model was used to estimate preferences and WTP for medication attributes.

Results: In all, 247 men completed the survey. Men were willing to trade-off symptom improvements and treatment side effects. Men preferred medications that reduced urinary urgency and reduced day- and nighttime urinary frequency. Men preferred medications without side effects (base-case level), but did not care about the number of tablets per day. WTP for symptomatic improvement was $£ 25.33 /$ month for reduced urgency (urge incontinence to mild urgency), and $£ 6.65 /$ month and $£ 1.39 /$ month for each unit reduction in night- and daytime urination frequency, respectively. The sexual and nonsexual side effects reduced WTP by up to $£ 30.07 /$ month. There was significant heterogeneity in preferences for most attributes, except for reduced urinary urgency from urge incontinence to mild urgency and no fluid during ejaculation (dry orgasm). Conclusion: To compensate for side effects, a medicine for lower urinary tract symptoms/ benign prostatic hyperplasia must provide a combination of benefits, such as reduced urgency of urination plus reduced nighttime and/or reduced daytime urination.

Keywords: benign prostatic hyperplasia, discrete choice experiment, erectile dysfunction, lower urinary tract symptoms, storage symptoms, urge incontinence

\section{Introduction}

Lower urinary tract symptoms (LUTS) are prevalent in aging men, with $\sim 90 \%$ of men aged 50 to 80 years suffering from potentially bothersome symptoms. ${ }^{1}$ Presenting symptoms include storage symptoms (ie, daytime urinary frequency, nocturia, urgency, urinary incontinence), voiding symptoms (ie, slow stream, splitting or spraying, intermittency, hesitancy, straining, terminal dribble), and/or post-micturition symptoms (sensation of incomplete emptying, post-micturition dribble). ${ }^{1}$ All three symptoms are found in one-third of men with LUTS, ${ }^{2}$ but storage symptoms have been reported to be the most bothersome. ${ }^{1,3,4}$

The mechanisms leading to the development of LUTS are multifactorial..$^{5}$ Benign prostatic hyperplasia (BPH) is reported to be a common cause of $\operatorname{LUTS}^{6,7}$ and $25 \%$ to
Correspondence: Colette Mankowsk Astellas Pharma Europe Ltd., Astellas Medical Affairs, EMEA, HEOR, 2000 Hillswood Drive, Chertsey, Surrey KTI6 OPS, UK

Tel +44 7881940638

Email colette.mankowski@astellas.com 
$50 \%$ of men with BPH have LUTS. ${ }^{1,8}$ LUTS associated with $\mathrm{BPH}$ (LUTS/BPH) is reported to negatively affect quality of life, daily activities, and general health. ${ }^{9,10}$ LUTS/BPH has also been linked to sexual dysfunction (eg, erectile dysfunction) $)^{11,12}$ and psychological dysfunction (eg, depression/anxiety $)^{9,13}$ in men.

Drug treatment is recommended for men with moderateto-severe LUTS, that is, those with an International Prostate Symptom Score (IPSS) $\geq 8$, to provide symptomatic relief when conservative management strategies have been unsuccessful or are not appropriate. ${ }^{1,5}$ Drug treatment options include $\alpha_{1}$-blockers, $5 \alpha$-reductase inhibitors (5-ARIs), antimuscarinics, and phosphodiesterase type 5 inhibitors. ${ }^{1,5}$ Combination therapy should be considered for men who have unresolved symptoms with monotherapy, for example, an $\alpha_{1}$-blocker plus an antimuscarinic or a 5-ARI. ${ }^{1,5}$

Patient preferences are an important consideration in the treatment of LUTS/BPH. ${ }^{5,14}$ Physicians should involve patients in the decision-making process to limit potential subsequent regret by the patient regarding some aspect(s) of the initiated treatment strategy, ${ }^{15}$ especially as patients' and physicians' preferences may not always be aligned. ${ }^{16}$ Discrete choice experiments (DCEs) are a common method to elicit patients' preferences to understand what aspects of symptoms and treatment are important to patients and the relative importance of these factors. ${ }^{17}$ Treatment choices require trade-offs between treatment benefits and side effects; DCEs are designed to capture and quantify these trade-offs. DCEs are being increasingly used to assist with health care decision making during the regulatory process. Evaluation of patient preferences is recommended by the US Food and Drug Administration ${ }^{18}$ and the German Institute for Quality and Efficiency in Health Care; the latter explicitly encourages the use of DCEs. ${ }^{19}$ The European Medicines Agency also advocates consideration of patients' assessments of the risks and benefits of medications through the use of quantitative methods. ${ }^{20}$ DCEs have been used to assess men's preferences for treatments for LUTS/BPH, ${ }^{21} \mathrm{BPH},{ }^{22}$ and overactive bladder. ${ }^{23}$ The previous study in LUTS/BPH used community dwelling men aged $\geq 40$ years in the UK and, therefore, the present study is the first DCE that has focused specifically on men with symptoms of LUTS/BPH.

In the present study, a DCE was conducted in men with LUTS/BPH with the following objectives: 1) to explore men's preferences for attributes of medications for LUTS/ $\mathrm{BPH} ; 2$ ) to estimate their willingness to pay (WTP), a monetary measure of benefit for attributes of medications; 3 ) to determine the trade-offs they are prepared to make between the benefits and side effects of medication; and 4) to explore variations in preferences for attributes of medications.

\section{Subjects and methods}

DCEs are based on the assumption that medications are valued by patients because of their characteristics or attributes. ${ }^{24}$ In our DCE, medications (A, B, or no medicine) were described by a set of attributes (eg, symptom improvements, side effects, and cost) that differed in their attribute levels (eg, variations in extent of symptom improvement, presence or absence of side effects), thereby creating different scenarios associated with LUTS/BPH. Men were asked to hypothetically choose the medication they preferred in a series of such choice tasks. From these choices, preferences for medication were inferred, allowing the estimation of: relative importance of the attributes; trade-offs made between attributes; and WTP for attributes.

\section{Attributes and levels}

Following best practice recommendations, ${ }^{25}$ qualitative methods were used to select attributes and levels for the DCE. The LUTS/BPH medications in our study were described by seven attributes and corresponding levels (Table 1). These attributes and levels were identified from an earlier qualitative research phase of the study (ie, literature review

Table I Attributes and levels in the DCE

\begin{tabular}{|c|c|}
\hline Attribute & Level \\
\hline Daytime frequency of urination ${ }^{a}$ & Eight, ten, 12 , or 14 times \\
\hline Nighttime frequency of urination ${ }^{a}$ & One, two, three, or four times \\
\hline $\begin{array}{l}\text { Urgency of urination - when you } \\
\text { need to urinate you usually... }\end{array}$ & $\begin{array}{l}\text { Have to rush to the toilet and } \\
\text { leak before you get there (urge } \\
\text { incontinence) } \\
\text { Cannot postpone and have to rush } \\
\text { to the toilet in order not to wet } \\
\text { yourself (severe urgency) } \\
\text { Can postpone for a short while, } \\
\text { without fear of wetting yourself } \\
\text { (moderate urgency) } \\
\text { Can postpone as long as necessary, } \\
\text { without fear of wetting yourself } \\
\text { (mild urgency) }\end{array}$ \\
\hline Sexual side effects & $\begin{array}{l}\text { No sexual side effects }{ }^{\mathrm{b}} \\
\text { No fluid during ejaculation } \\
\text { (dry orgasm) } \\
\text { Decreased sexual desire } \\
\text { Erectile dysfunction }\end{array}$ \\
\hline Nonsexual side effects & $\begin{array}{l}\text { No nonsexual side effects } \\
\text { Dry mouth } \\
\text { Headaches } \\
\text { Dizziness }\end{array}$ \\
\hline $\begin{array}{l}\text { Number of tablets } \\
\text { Cost per month }\end{array}$ & $\begin{array}{l}\text { One or two tablets per day } \\
£ 5, £ 10, £ 20 \text {, or } £ 40\end{array}$ \\
\hline
\end{tabular}

Notes: aFrequency attributes enter the statistical analysis as deviation from the no-treatment alternative; 'base-case level; cincludes prescription fees, travel, and absenteeism from work. Note that for urgency of urination, the extended text is what the men read in the survey, while the short labels in brackets are used in the paper for ease of reading.

Abbreviation: DCE, discrete choice experiment. 
and online discussion groups). Briefly, a structured literature review was conducted to find background information on LUTS/BPH and ensure that the subsequent study stages were based on existing evidence. Medline and Cochrane Database of Systematic Reviews were searched for articles in English that were published in 1991-2013. Combinations of the following search terms were used: "benign prostatic hyperplasia", "prostatic hyperplasia", "choice behavior", "patient preference", "decision making", "patient participation", and "attitude to health". The search was augmented by searching the reference lists of the identified literature. The abstracts (where available) of all publications were read for relevance and the content of documents collected. A total of 362 unique papers were identified (after excluding 72 duplicates).

Five moderated asynchronous online discussion groups were used to collect qualitative data about men's experiences of LUTS/BPH. Each discussion group lasted for 5 days and was hosted online on a secure and password protected bulletin board. Men residing in the UK with an IPSS score $\geq 8$ were invited to take part in the discussion groups. The men $(n=48)$ registered to a bulletin board with an anonymous username. Each day, a question about LUTS/BPH and its treatment was posed to and discussed by the men (day 1: LUTS/BPH and its effect on quality of life; day 2: management of symptoms; day 3: side effects of treatment; day 4 : consultation with a doctor; and day 5: concluding comments). These questions were informed by the literature review. The discussions were downloaded and analyzed independently by three researchers using an inductive thematic analysis. ${ }^{26}$

The attributes and levels included in the DCE were those most relevant to men with LUTS/BPH and were identified in two separate researcher workshops based on findings from the literature review and the qualitative analysis. "Daytime frequency of urination" (or daytime urinary frequency) levels ranged from eight to 14 times based on evidence that the median urinary frequency was seven times in 24 hours (range 2 to 21 ) in asymptomatic men, with 95\% voiding fewer than 12 times daily. ${ }^{27}$ The "nighttime frequency of urination" (nocturia) range was based on the IPSS instrument (range 0 to 5) and a study that reported data from 24-hour voiding diaries (range 0 to 4$).^{28}$ The levels of "urgency of urination" (urinary urgency) were adapted from the validated Patient Perception of Intensity of Urgency Scale. ${ }^{29,30}$ The attributes and levels for the sexual side effects (hypoactive sexual desire, as well as erectile and ejaculatory dysfunction) and nonsexual side effects (headaches, dizziness, and dry mouth), were based on the reported side effects of current LUTS/BPH medications, including $\alpha_{1}$-blockers, 5-ARIs, antimuscarinics, and phosphodiesterase type 5 inhibitors. ${ }^{1,5,31-34}$
Two of the attributes were not identified from the literature review and online discussion groups: number of daily tablets and cost of medication. Men may receive combination therapy for persistent LUTS/BPH, and therefore have preferences for the number of tablets to improve symptoms. The cost attribute was included to allow estimation of WTP for marginal changes in attribute levels. This attribute was framed as the total cost for men, including any prescription fees, travel expenses and absenteeism. The range of levels for the cost attribute was derived from earlier related studies ${ }^{21,35}$ and adjusted for inflation using the consumer price index. This range was tested in the pilot study in two ways: by examining the proportion of men never selecting a treatment in the DCE choice sets and including a payment card contingent valuation instrument.

\section{Experimental design and survey structure}

The attributes and levels resulted in 8,192 $\left(4^{6} \times 2^{1}\right)$ different possible combinations of medication. To reduce this number for presentation to men in a survey, a D-efficient design was generated. ${ }^{36}$ In total, 30 choice sets (grouped into three sets of ten choice sets) were selected to reduce the burden of the survey for men. Each choice set included two different medicine options and a no medicine option (ie, continue with the baseline scenario described). Figure 1 presents an example choice set.

The questionnaire included four sections. Section 1: men were provided with information (text and pictures) about LUTS/BPH and then asked three multiple-choice questions to determine the level of bother from their urinary symptoms. These were measured on an 11-point scale (range, $0=$ not at all bothered to $10=$ very bothered; a “don't know" option was also included). Men were also asked if they had ever visited a doctor about LUTS/BPH; were they currently taking medication to treat LUTS/BPH; and what treatments were received. Section 2: men considered a set of LUTS/BPH symptoms and were presented with questions about each of the seven attributes, one by one, to familiarize themselves with the attributes used in the DCE. Section 3: the DCE choice sets followed by debriefing questions about how difficult/realistic they found the choice tasks and whether they considered all of the medication attributes when making their choices. Section 4: men were asked questions about their socioeconomic characteristics and to complete the validated Beliefs about Medication Questionnaire. ${ }^{37}$ At the end of the survey, men were invited to provide any comments they had about the questionnaire.

Ethical approval for this study was granted by the College of Life Science and Medicine, University of Aberdeen, College Ethics Research Board (CERB), November 1, 2013 - CERB/2013/8/942. The full survey is available from the corresponding author on request. 
Please imagine this situation:

- You have to urinate 14 times during the day. When you need to urinate you usually have to rush to the toilet and leak before you get there. During the night you wake up four times to go to the bathroom and urinate.

- You do not take any medicine to treat your symptoms. However, your general practioner has told you that there are medicines available that can improve the symptoms described above. These medicines, however, may have side effects.

Please compare the medicines and tick which, if any, you would take:

\begin{tabular}{lccc} 
Description & Medicine A & Medicine B \\
Daytime frequency of urination & Eight times & 14 times & No medicine \\
\hline Nighttime frequency of urination & Three times & One time & Four times \\
\hline Urgency - when you need to urinate & $\begin{array}{l}\text { Have to rush to the } \\
\text { toilet and leak before } \\
\text { you usually... }\end{array}$ & $\begin{array}{c}\text { Cannot postopone and have } \\
\text { to rush to the toilet in order } \\
\text { you get there }\end{array}$ & Have to rush to the toilet and leak \\
Sexual side effects of medicine & No sexual side effects & Decreased sexual desire & You do not have any side effects \\
\hline Nonsexual side effects of medicine & Dry mouth & Headaches & Onou do not have any side effects \\
\hline Number of tablets per day & Two tablets & You do not take any medicine & $£ 0$
\end{tabular}

Please select your answer here:

Figure I Example DCE choice task.

Abbreviation: DCE, discrete choice experiment.

\section{Participants and recruitment}

The DCE was a self-administered online survey and participation was voluntary; the DCE survey was conducted during March 19-26, 2014. The target population was 300 men living in the UK, recruited from the online panel of a market research company. Men invited to take part in the survey (identified from screening questions) were aged $\geq 45$ years and had moderateto-severe LUTS/BPH, that is, self-reported IPSS $\geq 8$. These inclusion criteria were selected based on a reported increased prevalence of storage symptoms in men aged $\geq 45$ years $^{1}$ and the IPSS categorization of LUTS as moderate or severe (scores of 8-19 or 20-35, respectively). ${ }^{1}$ The invited men received a detailed information sheet about the survey with a hyperlink. We assumed that by clicking on the hyperlink men consented to taking part in the study. Men were free to withdraw at any point without having to give any reason(s). Men received a reward if they completed the 15-minute survey (£1.50).

The DCE was pilot tested among a subgroup of 63 men to assess the clarity of wording used in the survey, as well as to check the appropriateness of the attributes and levels. The mean WTP for treatment using a payment card was $£ 15$, and more than a third of men always chose the no medicine option. Based on these responses, the range of the cost attribute was lowered from $£ 15, £ 30, £ 50$, and $£ 75$ to $£ 5, £ 10$, $£ 20$, and $£ 40$ in the final DCE.

\section{Data analysis}

In the DCE, each man $(i)$ was presented with a choice between three alternative actions $(m)$, that is, taking medicine A, taking medicine $\mathrm{B}$, or taking no medicine. Men were assumed to choose the alternative (ie, their most preferred option) that provided them with the highest utility (ie, overall benefit) in terms of symptom improvement, side effects, number of tablets, and cost (ie, the attributes included in the DCE). The utility $\left(u_{i m}\right)$ that a man receives from an alternative is a function of the characteristics included in the DCE and an error term $\left(\varepsilon_{i m}\right)$ :

$$
\begin{aligned}
u_{i m}= & \beta_{0} \\
& +\left(\beta_{1}+\sigma_{1 i}\right) \text { daytime frequency }_{i m} \\
& +\left(\beta_{2}+\sigma_{2 i}\right) \text { nighttime frequency }_{i m} \\
& +\left(\beta_{3}+\sigma_{3 i}\right) \text { mild urgency }_{i m} \\
& +\left(\beta_{4}+\sigma_{4 i}\right) \text { moderate urgency }_{i m} \\
& +\left(\beta_{5}+\sigma_{5 i}\right) \text { severe urgency }_{i m} \\
& +\left(\beta_{6}+\sigma_{6 i}\right) \text { no fluid during ejaculation sexual side } \\
& + \text { effect }_{i m} \\
& +\left(\beta_{7}+\sigma_{7 i}\right) \text { decreased desire sexual side effect }_{i m} \\
& +\left(\beta_{8}+\sigma_{8 i}\right) \text { erectile dysfunction sexual side effect }_{i m} \\
& +\left(\beta_{9}+\sigma_{9 i}\right) \text { dry mouth nonsexual side effect }_{i m} \\
& +\left(\beta_{10}+\sigma_{10 i}\right) \text { headache nonsexual side effect }_{i m} \\
& +\left(\beta_{11}+\sigma_{11 i}\right) \text { dizziness nonsexual side effect }_{i m} \\
& +\left(\beta_{12}+\sigma_{12 i}\right) \text { number of tablets }_{i m} \\
& +\beta_{13} \text { cost per month }_{i m} \\
& +\varepsilon_{i m}
\end{aligned}
$$

$\beta_{0}$ is a constant term that denotes men's general preference for medication versus no medication. Given dummy variables are used to analyze the categorical variables (later); the constant term also values these reference categories.

In the estimated model, each attribute can be associated with two coefficients, one representing the average utility of the attribute $\left(\beta_{1}\right.$ to $\left.\beta_{13}\right)$, and another representing individual-specific preference variation for the attributes $\left(\sigma_{1 i}\right.$ to $\left.\sigma_{12 i}\right)$. These individual-specific preference variations allow 
that not all men will have the same preferences for medication and provide a measure of the variation in preferences in the population. $\sigma_{1 i}$ to $\sigma_{12 i}$ represents preference variation in the sample of men; if these coefficients are significant, this implies that preferences vary across the sample.

The interpretation of the average utility coefficient depends on the unit of measurement of the attribute. $\beta_{1}$ and $\beta_{2}$ represent the effect of a one-time reduction in day- and nighttime frequency of urination, respectively (and are modeled as continuous variables). The urgency attribute, side effects attributes, and number of tablets attributes were coded as dummy variables. In this case, the coefficients representing the average utility are interpreted relative to the reference categories - these are "urinary incontinence" for the urinary urgency attribute, "none" for both the sexual and nonsexual side effects attributes, and one tablet per day for the number of tablets attribute. $\beta_{13}$ indicates the effect of a $£ 1$ increase in the cost of treatment. The signs (+/-) of the coefficients, representing average utility, indicate whether a change in the attribute as described earlier has a positive or negative effect on medication utility. DCE responses were analyzed using a mixed-logit model; ${ }^{38}$ (Supplementary material).

From the mixed-logit results, we calculated WTP estimates, which show the monetary amounts that men are willing to pay per month for a unit change in each of the significant attributes. This placed all attributes on a common and meaningful metric (money), which allows the relative importance of each attribute as well as strength of preference and the trade-offs men make between attributes to be compared. WTP is calculated as the ratio of the average utility coefficient for the attribute and negative of the coefficient for the cost attribute. For example, $\left(\beta_{1} /-\beta_{13}\right)$ is men's WTP for one less daytime urination, while $\left(\beta_{8} /-\beta_{13}\right)$ is men's WTP to avoid the erectile dysfunction sexual side effect. Confidence intervals for WTP estimates were calculated using the Delta method..$^{39}$ The WTP estimates were also used to assess the trade-offs that men were willing to make between symptom improvements and the side effects of medications.

\section{Results}

\section{Men's characteristics}

A total of 5,212 individuals were invited to participate and 1,097 opened the online survey (ie, clicked the hyperlink). Of those who opened the DCE, 450 individuals did not meet the eligibility criteria, 136 met the criteria but were excluded because the quota was full, and 201 only partially completed the survey. A total of 310 men completed the survey ( 63 men in the pilot sample and 247 in the final sample); responses from the final sample of 247 men were used for analysis.
The mean age of the sample was 62.32 years, $51.01 \%$ of men had their day-to-day activities limited because of a health problem or disability, and $46.15 \%$ of men were retired (Table 2). The reported mean IPSS of the population was 15.69 (standard deviation 5.99). In addition, men were generally bothered by urinary symptoms, more during the night (mean score 5.86) than the day (mean score 4.92) and by urinary urgency (mean score 5.73). Approximately half of the men had spoken to a doctor (45.34\%) and less than a third received medication for their urinary symptoms $(26.32 \%)$; a summary of prior medications is shown in Table 3 .

\section{Estimation results}

A total of 216 men (87.5\%) stated that they considered all of the presented attributes. Across all of the choices in the DCE,

Table 2 Baseline socioeconomic and disease characteristics

\begin{tabular}{|c|c|c|}
\hline Characteristic & Category & Data \\
\hline$\overline{\text { Age, n (SD) }}$ & - & $62.32(9.05)$ \\
\hline \multicolumn{3}{|l|}{ Health, n } \\
\hline \multirow[t]{3}{*}{ Day-to-day activities } & Limited a lot & $32(12.96 \%)$ \\
\hline & Limited a little & $94(38.06 \%)$ \\
\hline & No & 121 (48.99\%) \\
\hline Suffer from any & Yes & I 42 (57.49\%) \\
\hline chronic illness & No & 105 (42.51\%) \\
\hline \multirow[t]{6}{*}{ Occupation, ${ }^{\mathrm{a}} \mathrm{n}$} & Employed/self-employed & $99(40.08 \%)$ \\
\hline & Unemployed & $21(8.50 \%)$ \\
\hline & Retired (receiving pension) & $114(46.15 \%)$ \\
\hline & Looking after home or family & I 8 (7.29\%) \\
\hline & Long-term sick or disabled & 22 (8.91\%) \\
\hline & Other & 14 (5.67\%) \\
\hline \multirow[t]{6}{*}{ Annual income, $n$} & $\leq \notin 10,399$ & $27(10.93 \%)$ \\
\hline & $£ 10,400-£ 20,799$ & $53(21.46 \%)$ \\
\hline & $£ 20,800-£ 31,199$ & $63(25.51 \%)$ \\
\hline & $£ 31,200-£ 51,999$ & $72(29.15 \%)$ \\
\hline & $\geq £ 52,000$ & 18 (7.29\%) \\
\hline & Prefer not to say & $14(5.67 \%)$ \\
\hline Bothered by urinary & Daytime frequency & $4.92(\mathrm{SD}, 2.49)$ \\
\hline \multirow[t]{2}{*}{ symptoms, ${ }^{b}$ mean } & Nighttime frequency & $5.86(\mathrm{SD}, 2.50)$ \\
\hline & Urgency & $5.73(\mathrm{SD}, 2.56)$ \\
\hline Severity of urinary & Moderate (IPSS 8-19) & $182(73.68 \%)$ \\
\hline symptoms, $\mathrm{n}$ & Severe (IPSS 20-35) & $65(26.32 \%)$ \\
\hline \multirow[t]{7}{*}{ IPSS quality of life, n } & Delighted & $4(1.62 \%)$ \\
\hline & Pleased & $8(3.24 \%)$ \\
\hline & Mostly satisfied & $40(16.19 \%)$ \\
\hline & Mixed & $102(41.30 \%)$ \\
\hline & Mostly dissatisfied & $52(21.05 \%)$ \\
\hline & Unhappy & 31 (12.55\%) \\
\hline & Terrible & 10 (4.05\%) \\
\hline \multirow[t]{3}{*}{ Spoken to doctor, $\mathrm{n}$} & Yes & I I 2 (45.34\%) \\
\hline & No & I 34 (54.25\%) \\
\hline & Do not know/could not say & I $(0.40 \%)$ \\
\hline Received medical & Yes & $65(26.32 \%)$ \\
\hline \multirow{2}{*}{ treatment, $\mathrm{n}$} & No & $45(18.22 \%)$ \\
\hline & Do not know/could not say & $2(0.01 \%)$ \\
\hline
\end{tabular}

Notes: aSome men reported more than one occupation, therefore, percentages add to $>100 \%$; 'based on a bothersome rating scale of 0-10 (plus an 'I don't know' option).

Abbreviations: IPSS, International Prostate Symptom Score; SD, standard deviation. 
Table 3 Previous treatments for urinary symptoms $(n=65)$

\begin{tabular}{|c|c|c|}
\hline Drug & $\begin{array}{l}\text { Frequency, }{ }^{a} \\
n\end{array}$ & $\begin{array}{l}\text { Relative } \\
\text { frequency (\%) }\end{array}$ \\
\hline \multicolumn{3}{|l|}{$\alpha_{1}$-blockers } \\
\hline Tamsulosin & 29 & 44.6 \\
\hline Doxazosin & 6 & 9.2 \\
\hline Alfuzosin & 4 & 6.2 \\
\hline Terazosin & 2 & 3.1 \\
\hline \multicolumn{3}{|l|}{$5 \alpha$-reductase inhibitor } \\
\hline Finasteride & 12 & 18.5 \\
\hline Dutasteride & 2 & 3.1 \\
\hline \multicolumn{3}{|l|}{ Antimuscarinic } \\
\hline Oxybutinin & 5 & 7.7 \\
\hline Solifenacin & 3 & 4.6 \\
\hline Tolterodine & 2 & 3.1 \\
\hline Flavoxate & 2 & 3.1 \\
\hline Darifenacin & I & 1.5 \\
\hline Propiverine & 1 & 1.5 \\
\hline \multicolumn{3}{|l|}{ Combination therapy } \\
\hline Tamsulosin plus dutasteride & 6 & 9.2 \\
\hline
\end{tabular}

Note: ${ }^{\mathrm{a} T e n}$ men had received two previous treatments.

$25.71 \%$ of men chose medication A, $32.75 \%$ chose medication B, and $41.54 \%$ chose no medication. Furthermore, $12.55 \%$ of men always chose the "no medicine" alternative compared to $21.05 \%$ of men who always chose one of the medicines (either medicine A or medicine B).
The regression coefficients were statistically significant at a $5 \%$ level for day- and nighttime urinary frequency, two of three attribute levels for urinary urgency, all sexual side effects, two of three attribute levels for nonsexual side effects, and the cost of medication (Table 4). The positive coefficients indicate that men preferred reductions in the frequency of urination both during the day and at night, as well as reductions in urgency of urination from urge incontinence (base case) to moderate and mild urgency. The negative coefficients for sexual and nonsexual side effects and cost per month showed that, on average, men preferred medication without these attributes.

Three regression coefficients were not statistically significant: men did not distinguish between urge incontinence and severe urgency, between taking one or two tablets per day, or viewed dry mouth as something to avoid. These results imply that, on average, these attributes did not influence men's choice of medication.

There was a statistically significant preference variation in the population for several attributes (Table 4): reductions in day- or nighttime frequency; reductions in urinary urgency from urge incontinence to severe or moderate urgency; the sexual side effects of decreased sexual desire and erectile

Table 4 Mixed-logit regression coefficients, willingness-to-pay estimates, and standard deviations of significant coefficients

\begin{tabular}{|c|c|c|c|c|c|c|}
\hline Attribute & $\begin{array}{l}\text { Regression } \\
\text { coefficient }(\beta)\end{array}$ & $P$-value & $\begin{array}{l}\text { Standard } \\
\text { deviation }(\sigma)\end{array}$ & $P$-value & WTP & $95 \% \mathrm{Cl}$ \\
\hline Constant $^{\mathrm{a}}$ & -0.377 & 0.212 & 2.77 I抻 & $<0.001$ & NS & NS \\
\hline Daytime frequency ${ }^{b}$ & $0.080^{\ddagger}$ & 0.002 & $0.114^{\ddagger \ddagger}$ & $<0.001$ & $£ 1.39$ & $£ 0.55$ to $£ 2.23$ \\
\hline Nighttime frequency ${ }^{b}$ & $0.384^{\ddagger \ddagger}$ & 0.000 & $0.847^{\text {执 }}$ & 0.001 & $£ 6.65$ & $£ 4.36$ to $£ 8.94$ \\
\hline \multicolumn{7}{|l|}{ Urinary urgency ${ }^{\mathrm{a}}$} \\
\hline \multicolumn{7}{|l|}{ (Base case: urge incontinence) } \\
\hline Severe urgency & -0.164 & 0.376 & $1.255^{\text {抹 }}$ & $<0.00$ I & NS & NS \\
\hline Moderate urgency & 1.381 㧊 & 0.000 & $0.863^{\ddagger}$ & $<0.001$ & $£ 23.93$ & $£ \mid 7.36$ to $£ 30.51$ \\
\hline Mild urgency & $1.462^{\text {㧊 }}$ & 0.000 & 0.518 & 0.054 & $£ 25.33$ & $£ 19.00$ to $£ 31.67$ \\
\hline \multicolumn{7}{|l|}{ Sexual side effects ${ }^{\mathrm{a}}$} \\
\hline \multicolumn{7}{|l|}{ (Base case: no sexual side effects) } \\
\hline No fluid during ejaculation (dry orgasm) & $-0.969 \neq \ddagger$ & 0.000 & 0.316 & 0.534 & $-£ 16.76$ & $-£ 23.48$ to $-£ 10.11$ \\
\hline Decreased sexual desire & $-1.135^{\text {㧊 }}$ & 0.000 & $0.926^{\ddagger}$ & $<0.001$ & $-£ 19.66$ & $-£ 26.63$ to $-£ 12.68$ \\
\hline Erectile dysfunction & $-1.735^{\ddagger \ddagger}$ & 0.000 & $0.035^{\ddagger \ddagger}$ & $<0.001$ & $-£ 30.07$ & $-€ 38.01$ to $-€ 22.13$ \\
\hline \multicolumn{7}{|l|}{ Nonsexual side effects ${ }^{\mathrm{a}}$} \\
\hline \multicolumn{7}{|l|}{ (Base case: no nonsexual side effects) } \\
\hline Dry mouth & -0.042 & 0.748 & 0.135 & 0.662 & NS & NS \\
\hline Headaches & -0.939 㧊 & 0.000 & $0.785^{\ddagger}$ & 0.002 & $-£ \mid 6.26$ & $-£ 22.00$ to $-£ 10.52$ \\
\hline Dizziness & $-0.955^{\text {护 }}$ & 0.000 & $0.666^{\ddagger}$ & 0.016 & $-€ 16.54$ & $-£ 22.25$ to $-€ 10.83$ \\
\hline Number of tablets per day & 0.083 & 0.425 & Fixed coefficient & & NS & NS \\
\hline Cost per month & $-0.058^{\text {㧊 }}$ & 0.000 & Fixed coefficient & & & \\
\hline Log likelihood & $-1,862.062$ & & & & & \\
\hline Akaike information criterion & $3,776.123$ & & & & & \\
\hline McFadden $R^{2}$ & 0.21 & & & & & \\
\hline Adjusted McFadden $R^{2}$ & 0.20 & & & & & \\
\hline $\mathrm{N}$ (observations) & 7,410 & & & & & \\
\hline
\end{tabular}

Notes: ${ }^{\ddagger}<<0.05$; $¥ ¥ P<0.01$; ${ }^{\text {c}}$ coefficient is normally distributed; ${ }^{b}$ coefficient is log-normally distributed.

Abbreviations: $\mathrm{Cl}$, confidence interval; NS, not significant; WTP, willingness to pay. 
dysfunction; and the nonsexual side effects of headache and dry mouth. However, there were no statistically significant variations in preference for an improvement from urge incontinence to mild urgency. This may reflect the variation in the sample about the degree of improvement represented by a move from urge incontinence to severe or moderate urgency, and the agreement in the sample about the benefit of the largest improvement from urge incontinence to mild urgency. The side effect of dry mouth also showed no significant preference variation, implying this attribute was not important to men in our sample.

\section{WTP}

The value of reducing day- or nighttime frequency by one time was small compared to the value for a reduction of urgency and side effects (Table 4). In terms of symptom improvements, men were willing to pay more to reduce the frequency urination by one toilet visit at night compared with the day ( $£ 6.65 /$ month vs $£ 1.39 /$ month). Men were willing to pay more to reduce urgency of urination than to reduce frequency of urination, for example, reducing urgency of urination from urge incontinence to mild urgency was valued at $£ 25.33 /$ month; this urinary urgency reduction is equivalent to reducing nighttime frequency by four urination events (ie, $£ 25.33 / £ 6.65)$. All sexual side effects reduced the value of medication; erectile dysfunction was considered to be the worst ( $£ 30.07 /$ month). The other sexual side effects, no fluid during ejaculation (dry orgasm), and decreased sexual desire, had a similar impact on medication value as the nonsexual side effects of headaches and dizziness. Furthermore, the value of reduced urgency (to moderate or mild urgency) would compensate any one of the side effects, except for erectile dysfunction.

\section{Discussion}

This study estimated men's preferences for medication attributes of treatments for LUTS/BPH. In terms of symptom improvement, reducing urinary urgency was the most important benefit of medication, followed by a one-time reduction in night- and daytime urinary frequency. In terms of side effects, avoiding sexual and nonsexual side effects was also important to men; erectile dysfunction was perceived as the worst side effect. The results also showed preference variations in the importance of medication attributes for treatment choice in the sample.

Based on key findings from the earlier qualitative phase of this study, the DCE was designed to focus on the most bothersome symptoms (ie, storage symptom attributes of frequency and urgency) and men's experience of their symptoms and treatment. As such, this DCE did not consider markers of treatment failure (eg, acute urinary retention or surgery) or treatment outcomes (eg, time to achieve improved symptoms or reduced prostate size), endpoints specifically associated with $\alpha_{1}$-blockers and 5-ARIs, which have been reported to be important to men with $\mathrm{BPH}^{40,41}$ and included in the previously published DCEs of BPH. ${ }^{21,35}$ The attribute levels for nonsexual side effects were expanded versus the previously published DCEs to include dry mouth, headache, and dizziness. Overall, these changes versus previous DCEs in BPH were designed to ensure our DCE focused on men's experiences and make it more relevant to all currently recommended therapies.

Storage symptoms, which include urgency, increased daytime frequency, increased nighttime frequency, and urge incontinence, represent the most bothersome LUTS ${ }^{1,3,4}$ and are reported in $62 \%$ of men with LUTS. ${ }^{2}$ We found that the most valued attribute of medication was reduced urgency of urination from urge incontinence to moderate or mild levels. Men were willing to pay up to $£ 24-25 /$ month for the ability to postpone urination temporarily (moderate urgency) or as long as necessary, without fear of wetting themselves (mild urgency). In contrast, a change from urge incontinence to severe urgency (cannot postpone and have to rush to the toilet in order to not wet yourself) appeared to have little importance and men were not willing to pay for this level of change. Men also valued reductions in day- and nighttime frequency. These data are not unexpected given that storage symptoms are reported to impair quality of life $e^{42,43}$ and limit daily activities ${ }^{44}$ in men with LUTS.

The DCE showed that men prefer to avoid medications with sexual side effects and that erectile dysfunction has the strongest influence on choice, reducing the WTP by $£ 30.07$ per month. This is consistent with previous DCEs, which reported erectile dysfunction was the least desirable sexual side effect and confirmed the undesirability of decreased sexual desire and no fluid during ejaculation (dry orgasm). ${ }^{21,35}$ Our results suggest that restrictions on sexual activity, specifically described as an inability to be sexually active, have a large negative effect on men's quality of life.

Men preferred treatments without headache and dizziness, which are reported nonsexual side effects of $\alpha_{1}$-blockers and phosphodiesterase type 5 inhibitors. ${ }^{33,45,46}$ In contrast, the prospect of dry mouth, associated with antimuscarinic use, ${ }^{33}$ had a minimal impact on men's preferences. This could be due to the fact that headache/migraine and dizziness are reported to impact work- and/or social-related activities. ${ }^{47,48}$ It may also be because few men in our sample ( $n=14,5.67 \%)$ had previously received antimuscarinic agents. 
Trade-offs are likely required when considering the efficacy and side effect profiles of pharmacological treatment options available to men with LUTS/BPH. Considering the net benefit of a medicine for men based on the estimated WTP, a medicine targeting a mix of symptoms with a particular focus on reducing urgency of urination combined with reducing night-/daytime frequency is likely to provide the highest benefit for men. Such a combination of benefits may compensate for the negative impact of side effects. For example, a therapy that reduced urgency to moderate urgency and provided one less nighttime urination (combined WTP estimate, $£ 30.58 /$ month) has the potential to compensate for the side effect of erectile dysfunction (WTP estimate, $-£ 30.07 /$ month). In contrast, the WTP estimates suggest that a therapy which only reduced nighttime frequency by one or two episodes per night (£6.65/month) would not compensate for decreased sexual desire (-£19.66/month).

A potential limitation of our study was that the DCE was limited to seven attributes that included urgency but excluded other LUTS symptoms (ie, voiding and/or postmicturition) and other potential treatment-related factors as described earlier. However, increasing the number of attributes increases the difficulty of completing the tasks, ${ }^{49,50}$ meaning that respondents may provide less precise answers or may not consider all of the attributes. ${ }^{51,52}$ In addition, a greater number of attributes increases the number of choices needed to ensure the impact of each attribute can be identified in the statistical model. We consider that the selection of these seven attributes balances comprehensiveness of the symptoms and medication description and practicality of the survey administration. Another potential limitation of this DCE was that all surveys were completed online thereby excluding men without access to the Internet. However, the men were spread geographically across the UK limiting any potential regional bias and Internet usage in the UK is high, even in people aged $\geq 65$ years. ${ }^{53}$ The results of this study are not generalizable beyond the UK.

\section{Conclusion}

In conclusion, treatment choice and the efficacy and tolerability profiles of medication are important factors for men with moderate-to-severe LUTS/BPH. Receiving medicines that significantly reduce storage symptoms, such as urge incontinence and nighttime urinary frequency, is perceived as the most important benefit of medication. However, men would prefer to avoid medicines that are likely to elicit sexual and nonsexual side effects. This study also highlights that treatment decisions may be optimized by understanding what symptoms and treatment benefits/side effects are of the greatest concern to patients with LUTS/BPH.

\section{Acknowledgments}

HERU is supported by the Chief Scientist Office at the Scottish Government Health and Social Care Directorate. Sebastian Heidenreich acknowledges financial support from the Institute of Applied Health Science, University of Aberdeen. Medical writing support was provided by Tyrone Daniel from Bioscript Medical and was funded by Astellas Pharma Europe Ltd. Presented in part as a poster at the ISPOR 17th Annual European Congress, November 8-12, 2014, Amsterdam, the Netherlands. The poster's abstract was published in Value in Health. 2014;17(7):A472.

\section{Author contributions}

All authors contributed toward data analysis, drafting and critically revising the paper and agree to be accountable for all aspects of the work.

\section{Disclosure}

DI, SH, MR, and VW are employed by the University of Aberdeen and performed the research which was funded by Astellas; CM, CN and JN are employees of Astellas.

\section{References}

1. https://www.nice.org.uk/ [homepage on the internet]. London: National Institute for Health and Clinical Excellence (NICE); NICE clinical guidelines: CG97. Lower urinary tract symptoms: The management of lower urinary tract symptoms in men [updated 2010]. Available from: https:// www.nice.org.uk/guidance/cg97/evidence/full-guideline-245363870. Accessed August 19, 2015.

2. Sexton CC, Coyne KS, Kopp ZS, et al. The overlap of storage, voiding and postmicturition symptoms and implications for treatment seeking in the USA, UK and Sweden: EpiLUTS. BJU Int. 2009;103(Suppl 3): 12-23.

3. Peters TJ, Donovan JL, Kay HE, et al. The International Continence Society "benign prostatic hyperplasia" study: the botherosomeness of urinary symptoms. J Urol. 1997;157(3):885-889.

4. Abrams P, Manson J, Kirby M. Incidence and epidemiology of storage lower urinary tract symptoms. Eur Urol Rev. 2012;7:50-54.

5. Gravas S, Bachmann A, Descazeaud A, et al. Guidelines on the management of non-neurogenic male lower urinary tract symptoms (LUTS), incl. benign prostatic obstruction (BPO). European Association of Urology [guidelines on the internet]; 2015. Available from: http://uroweb.org/ wp-content/uploads/EAU-Guidelines-Non-Neurogenic-Male-LUTSGuidelines-2015-v2.pdf. Accessed August 19, 2015.

6. Auffenberg GB, Helfand BT, McVary KT. Established medical therapy for benign prostatic hyperplasia. Urol Clin North Am. 2009;36(4): $443-459, \mathrm{v}-\mathrm{vi}$.

7. Roehrborn CG. Benign prostatic hyperplasia: an overview. Rev Urol. 2005;7(Supp1 9):S3-S14.

8. Chapple CR, Roehrborn CG. A shifted paradigm for the further understanding, evaluation, and treatment of lower urinary tract symptoms in men: focus on the bladder. Eur Urol. 2006;49(4):651-658.

9. Coyne KS, Wein AJ, Tubaro A, et al. The burden of lower urinary tract symptoms: evaluating the effect of LUTS on health-related quality of life, anxiety and depression: EpiLUTS. BJU Int. 2009;103(Suppl 3):4-11. 
10. Speakman M, Kirby R, Doyle S, Ioannou C. Burden of male lower urinary tract symptoms (LUTS) suggestive of benign prostatic hyperplasia (BPH) - focus on the UK. BJU Int. 2015;115(4):508-519.

11. Rosen R, Altwein J, Boyle P, et al. Lower urinary tract symptoms and male sexual dysfunction: the multinational survey of the aging male (MSAM-7). Eur Urol. 2003;44(6):637-649.

12. Wein AJ, Coyne KS, Tubaro A, Sexton CC, Kopp ZS, Aiyer LP. The impact of lower urinary tract symptoms on male sexual health: EpiLUTS. BJU Int. 2009;103(Suppl 3):33-41.

13. Fourcade RO, Lacoin F, Roupret M, et al. Outcomes and general health-related quality of life among patients medically treated in general daily practice for lower urinary tract symptoms due to benign prostatic hyperplasia. World J Urol. 2012;30(3):419-426.

14. Oelke M, Bachmann A, Descazeaud A, et al. EAU guidelines on the treatment and follow-up of non-neurogenic male lower urinary tract symptoms including benign prostatic obstruction. Eur Urol. 2013; 64(1):118-140.

15. Aning JJ, Wassersug RJ, Goldenberg SL. Patient preference and the impact of decision-making aids on prostate cancer treatment choices and post-intervention regret. Curr Oncol. 2012;19(Suppl 3): S37-S44.

16. Emberton M. Medical treatment of benign prostatic hyperplasia: physician and patient preferences and satisfaction. Int J Clin Pract. 2010;64(10): 1425-1435.

17. Clark MD, Determann D, Petrou S, Moro D, de Bekker-Grob EW. Discrete choice experiments in health economics: a review of the literature. Pharmacoeconomics. 2014;32(9):883-902.

18. http://www.fda.gov/ [homepage on the internet]. Maryland: Food and Drug Administration. Guidance for Industry and Food and Drug Administration Staff: Factors to Consider When Making Benefit-Risk Determinations in Medical Device Premarket Approval and De Novo Classifications [updated 2012 October 1] Available from: http://www.fda.gov/downloads/MedicalDevices/ DeviceRegulationandGuidance/GuidanceDocuments/UCM296379. pdf. Accessed August 19, 2015.

19. https://www.iqwig.de/ [homepage on the internet]. Köln: Institut für Qualität und Wirtschaftlichkeit im Gesundheitswesen (IQWiG). Allgemeine Methoden Version 4.1 [updated 2013]. Available from: https:// www.iqwig.de/download/IQWiG_General_Methods_Version_\%20 4-1.pdf. Accessed August 19, 2015.

20. http://www.ema.europa.eu/ema/ [homepage on the internet]. London: European Medicines Agency; Road map to 2015. The European Medicine's Agency Contribution to Science, Medicines and Health [updated 2011]. Available from: http://www.ema.europa.eu/docs/en_GB/ document_library/Report/2011/01/WC500101373.pdf. Accessed August 19, 2015.

21. Watson V, Ryan M, Brown CT, Barnett G, Ellis BW, Emberton M. Eliciting preferences for drug treatment of lower urinary tract symptoms associated with benign prostatic hyperplasia. J Urol. 2004; 172(6 Pt 1):2321-2325.

22. Llewellyn-Thomas HA, Williams JI, Levy L, Naylor CD. Using a trade-off technique to assess patients' treatment preferences for benign prostatic hyperplasia. Med Decis Making. 1996;16(3):262-282.

23. Swinburn P, Lloyd A, Ali S, Hashmi N, Newal D, Najib H. Preferences for antimuscarinic therapy for overactive bladder. BJU Int. 2011; 108(6):868-873.

24. Ryan M, Bate A, Eastmond CJ, Ludbrook A. Use of discrete choice experiments to elicit preferences. Qual Health Care. 2001;10(Suppl 1): i55-i60.

25. Coast J, Al-Janabi H, Sutton EJ, et al. Using qualitative methods for attribute development for discrete choice experiments: issues and recommendations. Health Econ. 2012;21(6):730-741.

26. Ritchie J, Lewis J, McNaughton Nicholls C, Ormston R, editors. Qualitative Research Practice. A Guide for Social Science Students and Researchers. London: SAGE Publications Ltd; 2014.

27. Latini JM, Mueller E, Lux MM, Fitzgerald MP, Kreder KJ. Voiding frequency in a sample of asymptomatic American men. J Urol. 2004;172(3):980-984.
28. Fitzgerald MP, Brubaker L. Variability of 24-hour voiding diary variables among asymptomatic women. J Urol. 2003;169(1):207-209.

29. Notte SM, Marshall TS, Lee M, et al. Content validity and test-retest reliability of Patient Perception of Intensity of Urgency Scale (PPIUS) for overactive bladder. BMC Urol. 2012;12:26.

30. Cartwright R, Panayi D, Cardozo L, Khullar V. Reliability and normal ranges for the Patient's Perception of Intensity of Urgency Scale in asymptomatic women. BJU Int. 2010;105(6):832-836.

31. Naslund MJ, Miner M. A review of the clinical efficacy and safety of 5alpha-reductase inhibitors for the enlarged prostate. Clin Ther. 2007; 29(1):17-25.

32. van Dijk MM, de la Rosette JJ, Michel MC. Effects of alpha(1)adrenoceptor antagonists on male sexual function. Drugs. 2006;66(3): 287-301.

33. Hollingsworth JM, Wilt TJ. Lower urinary tract symptoms in men. BMJ. 2014;349:g4474.

34. Oefelein MG. Safety and tolerability profiles of anticholinergic agents used for the treatment of overactive bladder. Drug Saf. 2011;34(9): 733-754.

35. Eberth B, Watson V, Ryan M, Hughes J, Barnett G. Does one size fit all? Investigating heterogeneity in men's preferences for benign prostatic hyperplasia treatment using mixed logit analysis. Med Decis Making. 2009;29(6):707-715.

36. Kuhfeld W. Marketing Research Methods in SAS: Experimental Design, Choice, Conjoint and Graphical Techniques. North Carolina: SAS Institute Inc; 2009.

37. Horne R, Weinman J, Hankins M. The Beliefs about Medicines Questionnaire: The development and evaluation of a new method for assessing the cognitive representation of medication. Psychol Health. 1999;14(1):1-24.

38. Train K. Discrete Choice Methods with Simulation. New York Cambridge University Press; 2002.

39. Oehlert G. A note on the delta method. Am Stat. 1992;46(1):27-29.

40. Emberton M, Marberger M, de la Rosette J. Understanding patient and physician perceptions of benign prostatic hyperplasia in Europe: The Prostate Research on Behaviour and Education (PROBE) Survey. Int J Clin Pract. 2008;62(1):18-26.

41. Kaplan S, Naslund M. Public, patient, and professional attitudes towards the diagnosis and treatment of enlarged prostate: A landmark national US survey. Int J Clin Pract. 2006;60(10):1157-1165.

42. Engstrom G, Henningsohn L, Walker-Engstrom ML, Leppert J. Impact on quality of life of different lower urinary tract symptoms in men measured by means of the SF 36 questionnaire. Scand J Urol Nephrol. 2006;40(6):485-494.

43. Djavan B. Lower urinary tract symptoms/benign prostatic hyperplasia: fast control of the patient's quality of life. Urology. 2003;62(3 Suppl 1): 6-14.

44. Tang DH, Colayco D, Piercy J, Patel V, Globe D, Chancellor MB. Impact of urinary incontinence on health-related quality of life, daily activities, and healthcare resource utilization in patients with neurogenic detrusor overactivity. BMC Neurol. 2014;14:74.

45. Dolder CR. Dutasteride: a dual 5-alpha reductase inhibitor for the treatment of symptomatic benign prostatic hyperplasia. Ann Pharmacother. 2006;40(4):658-665.

46. Dutkiewics S. Efficacy and tolerability of drugs for treatment of benign prostatic hyperplasia. Int Urol Nephrol. 2001;32(3):423-432.

47. Mennini FS, Gitto L, Martelletti P. Improving care through health economics analyses: cost of illness and headache. J Headache Pain. 2008;9(4):199-206.

48. Bronstein AM, Golding JF, Gresty MA, et al. The social impact of dizziness in London and Siena. J Neurol. 2010;257(2):183-190.

49. DeShazo J, Fermo G. Designing choice sets for stated preference methods: the effects of complexity on choice consistency. J Environ Econ Manage. 2002;44(1):123-143.

50. Maddala T, Phillips KA, Reed Johnson F. An experiment on simplifying conjoint analysis designs for measuring preferences. Health Econ. 2003;12(12):1035-1047. 
51. Viney R, Savage E, Louviere J. Empirical investigation of experimental design properties of discrete choice experiments in health care. Health Econ. 2005;14(4):349-362.

52. Alemu M, Morkbak M, Olsen S, Jensen C. Attending to the reasons for attribute non-attendance in choice experiments. Environ Resour Econ. 2013;54(3):333-359.
53. https://www.ons.gov.uk/ [homepage on the internet]. London: Office for National Statistics. Internet Access Quarterly Update, Q1; 2014 [updated 2014 May 14]. Available from: http://www.ons.gov.uk/ons/ dcp171778_362910.pdf. Accessed August 19, 2015. 


\section{Supplementary material Description of mixed-logit model used to analyze discrete choice experiment responses}

This approach allows preferences for attributes to vary across individuals and requires the specification of a distribution for each coefficient hypothesized to vary across participants. The distribution of the coefficients of the day- and nighttime frequency attributes was assumed to be log normal, given that all respondents ought to prefer reductions in the frequency of urination. ${ }^{1,2}$ All other coefficients were assumed to have a normal distribution, allowing for both positive and negative effects on utility. The estimation was based on 3,000 Halton draws using Stata version 13 (StataCorp LP, College Station, TX, USA). ${ }^{3}$ A fixed parameter was assumed for the cost attribute, thus assuming all individuals had the same negative preference, and allowing easier estimation of willingness to pay for all other attributes. ${ }^{4}$

\section{References}

1. Hensher D, Rose J, Greene W. Applied Choice Analysis: A Primer. Cambridge, UK: Cambridge University Press; 2007.

2. Train K. Discrete Choice Methods with Simulation. New York: Cambridge University Press; 2002.

3. Hole AR. Fitting mixed logit models by using maximum simulated likelihood. Stata J. 2007;7(3):388-401.

4. Daly A, Hess S, Train K. Assuring finite moments for willingness to pay in random coefficient models. Transportation. 2012;39(1):19-31.

\section{Publish your work in this journal}

Patient Preference and Adherence is an international, peer-reviewed, open access journal that focuses on the growing importance of patient preference and adherence throughout the therapeutic continuum. Patient satisfaction, acceptability, quality of life, compliance, persistence and their role in developing new therapeutic modalities and compounds to optimize clinical outcomes for existing disease states are major areas of interest for the journal. This journal has been accepted for indexing on PubMed Central. The manuscript management system is completely online and includes a very quick and fair peer-review system, which is all easy to use. Visit http://www. dovepress.com/testimonials.php to read real quotes from published authors.

Submit your manuscript here: http://www.dovepress.com/patient-preference-and-adherence-journal 